\title{
Polyamines Mediate Uncontrolled Calcium Entry and Cell Damage in Rat Heart in the Calcium Paradox
}

\author{
Harold Koenig, Alfred D. Goldstone,* Jerome J. Trout, and Chung Y. Lu \\ Neurology Service, Veterans Administration Lakeside Medical Center, and Departments of Neurology and \\ of *Molecular Biology and Biochemistry, Northwestern University Medical School, Chicago, Illinois 60611
}

\begin{abstract}
Brief perfusion of heart with calcium-free medium renders myocardial cells calcium-sensitive so that readmission of calcium results in uncontrolled $\mathrm{Ca}^{2+}$ entry and acute massive cell injury (calcium paradox). We investigated the hypothesis that polyamines may be involved in the mediation of abnormal $\mathrm{Ca}^{2+}$ influx and cell damage in the calcium paradox. The isolated perfused rat heart was used for these studies. Calcium-free perfusion promptly ( $<5 \mathrm{~min}$ ) decreased the levels of polyamines and the activity of their rate-regulating synthetic enzyme, ornithine decarboxylase (ODC), and calcium reperfusion abruptly ( $<15-180 \mathrm{~s}$ ) increased these components. $\alpha$-Difluoromethylornithine (DFMO), a specific suicide inhibitor of ODC, suppressed the calcium reperfusion-induced increase in polyamines and the concomitant increase in myocardial cellular ${ }^{45} \mathrm{Ca}$ influx, loss of contractility, release of cytosolic enzymes, myoglobin, and protein, and structural lesions. Putrescine, the product of ODC activity, nullified DFMO inhibition and restored the calcium reperfusion-induced increment in polyamines and the full expression of the calcium paradox. Putrescine itself enhanced the reperfusion-evoked release of myoglobin and protein in the absence of DFMO. Hypothermia blocked the changes in heart ODC and polyamines induced by calcium-free perfusion and calcium reperfusion and prevented the calcium paradox. These results indicate that rapid $\mathrm{Ca}^{2+}$-directed changes in ODC activity and polyamine levels are essential for triggering excessive transsarcolemmal transport of $\mathrm{Ca}^{2+}$ and explosive myocardial cell injury in the calcium paradox.
\end{abstract}

\section{Introduction}

Calcium ions are important mediators of numerous processes required for the maintenance of normal cell structure and function, but they also participate in pathological processes that can lead to cell death. This is well exemplified in the cardiac myocyte that is dependent on extracellular $\mathrm{Ca}^{2+}$ for excitation-contraction coupling $(1,2)$, and the structural integrity of its plasma membrane (3), and is at the same time extremely vulnerable to perturbations of calcium homeostasis. In the calcium paradox, a short period of perfusion with calcium-free $(<50 \mu \mathrm{M})$ solution renders the heart cells $\mathrm{Ca}^{2+}$-sen-

Part of this work appeared in abstract form (1986. Fed. Proc. 45:940). Address reprint requests to Prof. Harold Koenig, Neurology Service, Veterans Administration Lakeside Medical Center, 333 E. Huron St., Chicago, IL 60611.

Received for publication 22 October 1986 and in revised form 30 April 1987.

The Journal of Clinical Investigation, Inc.

Volume 80, November 1987, 1322-1331 sitive so that readmission of $\mathrm{Ca}^{2+}$ results in lethal cell injury thought to be triggered by the entry of a large amount of $\mathrm{Ca}^{2+}$ into the cell (4-8). Despite much work, however, the molecular and cellular mechanisms underlying $\mathrm{Ca}^{2+}$ influx and calcium-mediated cell damage have remained elusive.

Th aliphatic polyamines putrescine, spermidine, and spermine, the major organic cations of cells, play an important role in cell growth, differentiation and replication in heart (9), as in other tissues $(10-12)$. Recent studies in our laboratory have revealed that a transient increase in the activity of ornithine decarboxylase (ODC), ${ }^{1}$ the first and rate-regulating enzyme of polyamine synthesis, and a rise in polyamine levels are very early events in cells stimulated by the hormones testosterone (13), 1-isoproterenol $(14,15)$, triiodothyrone $(16,17)$, and insulin $(18,19)$, as well as by membrane depolarization (20). This polyamine synthesis has been shown to be important for hormone- and depolarization-induced stimulation of $\mathrm{Ca}^{2+}$ fluxes and several $\mathrm{Ca}^{2+}$-dependent cell responses. These findings have led to a new model for signal transduction and stimulus-response coupling in which polyamines function as messengers to increase cytosolic $\mathrm{Ca}^{2+}$ concentration by stimulating transmembrane $\mathrm{Ca}^{2+}$ transport and mobilizing intracellular calcium $(13,14,21)$. In the present study we have examined the putative role of polyamines in the regulation of abnormal $\mathrm{Ca}^{2+}$ movements and the mediation of cellular injury in the calcium paradox. Our results indicate that calcium-free perfusion and calcium reperfusion cause rapid and profound changes in cardiac ODC and polyamine levels. These $\mathrm{Ca}^{2+}$-directed changes in ODC and polyamines appear to be instrumental in triggering the large amplitude movement of $\mathrm{Ca}^{2+}$ across the cell membrane leading to the calcium paradox.

\section{Methods}

Heart perfusion. Female Sprague-Dawley rats (200-300 g body wt) were injected intraperitoneally with $100 \mathrm{U}$ of heparin and $60 \mathrm{mg} / \mathrm{kg}$ pentobarbital. Hearts were rapidly excised and immersed in oxygenated buffer solution at $4^{\circ} \mathrm{C}$. The aorta was cannulated for retrograde perfusion of the heart by a nonrecirculating Langendorff technique using a modified Krebs-Henseleit ( $\mathrm{KH}$ ) medium containing (in $\mathrm{mM}$ ): $\mathrm{NaCl}, 118 ; \mathrm{KCl}, 4,74 ; \mathrm{MgSO}_{4}, 1.2 ; \mathrm{NaHCO}_{3}, 25 ; \mathrm{CaCl}_{2}, 2.5 ; \mathrm{KH}_{2} \mathrm{PO}_{4}$, 0.93 ; glucose, $10, \mathrm{pH} 7.4$. The $\mathrm{KH}$ medium was saturated with $95 \%$ $\mathrm{O}_{2}-5 \% \mathrm{CO}_{2}$, warmed to $37^{\circ} \mathrm{C}$, and delivered to the heart by a syringe pump (model 341A, Sage Instruments Div., Orion Research Inc., Cambridge, MA). Cardiac contractility was monitored by a Grass FT08 force-displacement transducer attached via a nylon ligature to the ventricular apex. The transducer output was displayed on a Kipp and Zonen BD 40 recorder.

${ }^{45} \mathrm{Ca}$ uptake. Myocardial ${ }^{45} \mathrm{Ca}$ uptake was measured by a modification of the method of Gotzsche (22). Briefly, hearts were perfused with

1. Abbreviations used in this paper: DFMO, difluoromethylornithine; KH, Krebs-Henseleit; ODC, ornithine decarboxylase. 
${ }^{45} \mathrm{Ca}(1 \mu \mathrm{Ci} / \mathrm{ml})$ in $\mathrm{KH}$ medium for $15 \mathrm{~s}-5 \mathrm{~min}$ followed by a $15-\mathrm{min}$ washout with calcium-free $\mathrm{KH}$ medium containing $0.5 \mathrm{mM}$ EGTA at $0^{\circ} \mathrm{C}$ to clear the vascular and extracellular compartments of ${ }^{45} \mathrm{Ca}$ and leave the cellular ${ }^{45} \mathrm{Ca}$ trapped within the myocardial cells. This method, which has been used for measurement of rapidly exchangeable cellular ${ }^{45} \mathrm{Ca}(23,24)$, as well as cellular ${ }^{45} \mathrm{Ca}$ uptake in the perfused beating heart $(22,25)$, is based on the principle that active transport processes have a much higher $\mathrm{Q}_{10}$ than passive diffusion. The ${ }^{45} \mathrm{Ca}$ uptake values obtained in control rat heart in the present experiments were comparable to those reported by Gøtzsche $(22,25)$.

Analytical methods. For biochemical measurements, hearts were freeze-clamped at $-186^{\circ} \mathrm{C}$ and stored at $-70^{\circ} \mathrm{C}$ until analyzed. ODC activity was assayed by a modification (13) of the method of Djurhuus (26). Tissue samples were homogenized in $\sim 5 \mathrm{vol}$ of $50 \mathrm{mM}$ sodium phosphate buffer, pH 7.2, containing $5 \mathrm{mM}$ dithiothreitol, $0.1 \mathrm{mM}$ EDTA, and $40 \mathrm{mM}$ pyridoxal phosphate. Homogenates were centrifuged at $12,000 \mathrm{~g}$ for $20 \mathrm{~min}$ at $4^{\circ} \mathrm{C}$ and the pellets were discarded. 0.1 $\mathrm{ml}$ of the supernatant was added to $0.1 \mathrm{ml}$ of incubation medium consisting of $50 \mathrm{mM}$ sodium phosphate buffer, $\mathrm{pH} 7.2,5 \mathrm{mM}$ dithiothretiol, $200 \mu \mathrm{M}$ pyridoxal phosphate, $0.1 \mathrm{mM}$ L-ornithine, and 0.3 $\mu \mathrm{Ci}\left[\left(3-{ }^{3} \mathrm{H}\right.\right.$ (n)-ornithine)] (20 Ci mmol${ }^{-1}$; New England Nuclear, Boston, MA). The tubes were incubated for $2 \mathrm{~h}$ at $37^{\circ} \mathrm{C}$ and then cooled to $4^{\circ} \mathrm{C} .40 \mu \mathrm{l}$ of incubation mixture was applied to Whatman P-81 cation exchange paper and paper strips were subjected to descending chromatography for $3 \mathrm{~h}$ with $0.1 \mathrm{M} \mathrm{NH}_{4} \mathrm{OH}$ to elute unreacted ornithine. The strips were dried and the spots corresponding to a putrescine standard detected by ninhydrin were cut out, placed in scintillation vials with 1 $\mathrm{ml}$ deionized water, and heated at $50^{\circ} \mathrm{C}$ for $2 \mathrm{~h} .10 \mathrm{ml}$ of Aquassure scintillation fluid (New England Nuclear) was added to each vial and the radioactivity was counted in a LS-250 liquid scintillation counter (Beckman Instruments, Fullerton, CA). Enzyme controls containing the complete assay mixture and boiled enzyme were run with each determination and the values subtracted from the experimental values. $\mathrm{ODC}$ activity was expressed as picomoles putrescine $\mathrm{H}^{-1}$. In the range in which determinations were made, $\mathrm{ODC}$ activity was linear with time and protein. For polyamine determinations, tissue samples were homogenized in $\sim 5 \mathrm{vol}$ of $0.2 \mathrm{M}$ perchloric acid and centrifuged at $10,000 \mathrm{~g}$ for $10 \mathrm{~min}$. The polyamines in the supernatants were separated by thin-layer chromatography of the dansylated adducts and measured by spectrofluorimetry (27). This assay was linear over a wide range of polyamine concentrations $(0.05-100 \mathrm{nmol} / 30 \mu \mathrm{l})$ with a coefficient of variation of $3 \%$ (at 0.1 and $1 \mathrm{nmol} / 30 \mu \mathrm{l}$ ), and a limit of detection of $25 \mathrm{pmol}$. For measurement of polyamines in coronary effluents, total effluents ( $\sim 25 \mathrm{ml} / 5 \mathrm{~min} \mathrm{Ca-free} \mathrm{perfusion)} \mathrm{were} \mathrm{lyo-}$ philized, taken up in $0.5 \mathrm{ml} \mathrm{H} \mathrm{H}_{2} \mathrm{O}$, dansylated, and $25-\mu \mathrm{l}$ aliquots were subjected to thin-layer chromatography. Creatine kinase, lactate dehydrogenase, and glutamate-oxaloacetate transaminase were assayed by an automated analyzer (American Monitor Corp., Indianapolis, IN). Myoglobin was determined by spectrophotometry $\left(\mathrm{A}_{434}-\mathrm{A}_{\mathbf{4 1 0}}\right)$. Protein was measured according to Lowry et al. (28). ${ }^{45} \mathrm{Ca}$ radioactivity was assayed by scintillation spectrometry. Data were expressed as means \pm SEM.

Electron microscopy and morphological evaluation. Hearts were fixed by perfusion through the aortic cannula with $3 \%$ glutaraldehyde in $0.1 \mathrm{M}$ cacodylate buffer, $\mathrm{pH} 7.3$, postfixed in $1 \%$ osmium tetroxide- $1.5 \%$ potassium ferricyanide in $0.1 \mathrm{M}$ cacodylate buffer, $\mathrm{pH} 7.3$, for $2 \mathrm{~h}$, dehydrated in graded concentrations of ethanol, cleared in propylene oxide, and embedded in epon. For quantitative assessment of cellular damage, $0.5-\mu \mathrm{m}$-thick sections were stained with toluidine blue and basic fuchsin (epoxy tissue stain, Electron Microscopy Sciences, Fort Washington, PA) and examined by light microscopy. A minimum of 500 myocardial cells in three blocks from each of four hearts in each treatment group were examined with a $40 \times$ oil immersion objective and classified as severely injured or intact. All slides were coded and examined blind. For examination of myocardial cell ultrastructure, thin sections were doubly stained with uranyl acetate and lead citrate and examined and photographed in a Hitachi HU-12 or L-600 electron microscope.
Experimental design. A typical experimental protocol consisted of the following groups of three to six hearts each: (a) control perfusions, in which hearts were perfused for 10 or 20 min with normal Ca-containing $\mathrm{KH}$ buffer; (b) Ca-free perfusion, in which hearts were perfused for 5 min with $\mathrm{KH}$ medium followed by 5 or $15 \mathrm{~min}$ of perfusion with Ca-free $\mathrm{KH}$ medium; (c) Ca reperfusion, in which following a 5 or 15 min Ca-free perfusion hearts were perfused with Ca-containing $\mathrm{KH}$ medium for various times (15 s-5 min); (d) Ca reperfusion + difluoromethylornithine (DFMO), in which the ODC inhibitor DFMO (5-10 $\mathrm{mM}$ ) was added to all perfused media; $(e)$ Ca reperfusion + DFMO + putrescine, in which DFMO and the putrescine (0.5-1 mM), the product of ODC activity, were added to all the media.

Materials. $\alpha$-DFMO was generously provided by Merrell-Dow Research Center, Cincinnati, OH. L- $\left[3-{ }^{3} \mathrm{H}(n)\right]$ ornithine, ${ }^{45} \mathrm{CaCl}_{2}$, and Aquasol came from New England Nuclear, and putrescine dihydrochloride from Sigma Chemical Co., St. Louis, MO. Sprague-Dawley rats were from Holtzman Co., Madison, WI. All other reagents were of the best analytical grade available.

\section{Results}

In the standard experimental protocol, hearts were perfused at $37^{\circ} \mathrm{C}$ with $\mathrm{KH}$ buffer for a 5 -min washout and equilibration period followed by a 5-min perfusion with calcium-free $\mathrm{KH}$ buffer containing $0.05 \mathrm{mM}$ EGTA. Readmission of calciumcontaining $\mathrm{KH}$ buffer consistently induced a total calcium paradox, as manifested by an irreversible loss of contractility, maximum release of enzymes and myoglobin (60-70\% of initial heart contents after 2 min of calcium repletion), and severe morphological damage affecting virtually all myocytes $(98 \pm 1.6 \%$ of total cells after 15 min of calcium repletion).

$O D C$ and polyamines. Heart ODC activity and polyamine concentrations were stable during perfusion with normal $\mathrm{KH}$ buffer containing $2.5 \mathrm{mM} \mathrm{CaCl}$ for at least $20 \mathrm{~min}$. Perfusion with calcium-free $\mathrm{KH}$ buffer containing $0.05 \mathrm{mM}$ EGTA consistently caused a $40-50 \%$ decrease in ODC activity and a $25-40 \%$ decrease in the levels of putrescine, spermidine, and spermine within $5 . \mathrm{min}$ (Figs. 1 and 2, Tables I and II). Prolonging the calcium-free perfusion to $15 \mathrm{~min}$ caused no further change in these constituents (Figs. 1 and 2, Tables I and II). Polyamines were not detected in coronary effluents collected during calcium-free perfusion, lyophilized, and taken up in small volume to increase the sensitivity of their detection, indicating that they were not released extracellularly. Readmission of calcium-containing $\mathrm{KH}$ buffer induced an abrupt $(<15 \mathrm{~s})$ rise in ODC activity that peaked at $30 \mathrm{~s}$ and then declined slightly, but remained elevated during a 5-min reperfusion (Fig. 1, Table II). Polyamine concentrations also rose promptly, the increase in putrescine and spermidine attaining significance at $15 \mathrm{~s}$, and spermine at $30 \mathrm{~s}$ (Fig. 2). The rank order of increase of the polyamines was putrescine $>$ spermidine $>$ spermine during $120 \mathrm{~s}$ of calcium repletion, at which time ODC and polyamine levels were restored to those found in hearts not subjected to calcium-free perfusion. $\alpha$-DFMO, ( 5 $\mathrm{mM}$ ), a suicide inhibitor of ODC (29), reduced the calcium reperfusion-induced increment in ODC by $80-85 \%$, and the increment in polyamines by $93-120 \%$ (Table II). Putrescine $(0.5 \mathrm{mM})$, the product of ODC activity, effectively circumvented DFMO inhibition and repleted heart polyamines during calcium reperfusion (Table II). Putrescine also increased ODC activity in the presence of DFMO.

Contractile function. To investigate the pathophysiological role of the changes in heart ODC and polyamine levels in the 


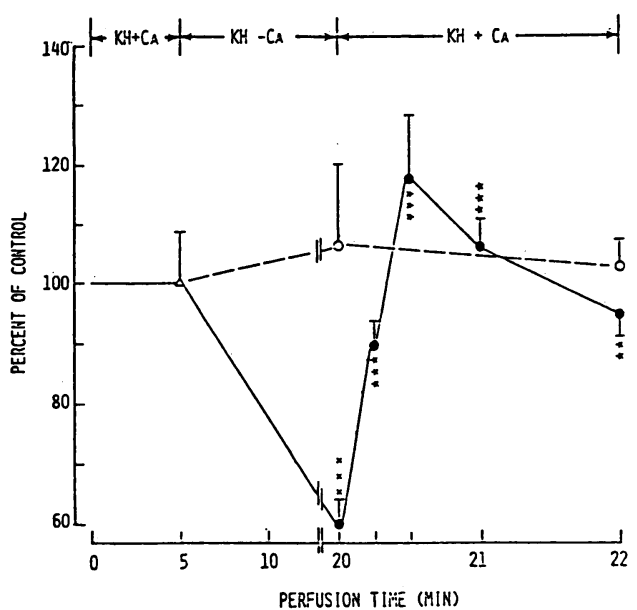

Figure 1. Effect of euthermic and hypothermic calcium-free perfusion and calcium reperfusion on heart ODC activity. Rat hearts were perfused for 5 min with calcium-containing $\mathrm{KH}$ medium $(\mathrm{KH}+\mathrm{Ca})$ for equilibration and washout followed by a 15-min perfusion with calcium-free $\mathrm{KH}(\mathrm{KH}-\mathrm{Ca})$ containing $0.05 \mathrm{~mm}$ EGTA at $37^{\circ} \mathrm{C}$ (solid circles) or $18^{\circ} \mathrm{C}$ (open circles), and reperfusion with $\mathrm{KH}$ medium. At the given times the hearts were freeze-clamped at $-186^{\circ} \mathrm{C}$ and analyzed for ODC, polyamines, and protein, as described in text. Experimental results are means $\pm \operatorname{SEM}(n=6$ hearts per time point). The control perfusion ODC value (open triangle, $100 \%$ on ordinate) at $5 \mathrm{~min}$ was $225 \mathrm{pmol} / \mathrm{h}$ per $\mathrm{mg}$ protein. ${ }^{\times \times \times} P<0.001$ vs. control perfusion. ${ }^{* *} P<0.01,{ }^{* * *} P<0.001$ vs. calcium-free perfusion value at $20 \mathrm{~min}$.

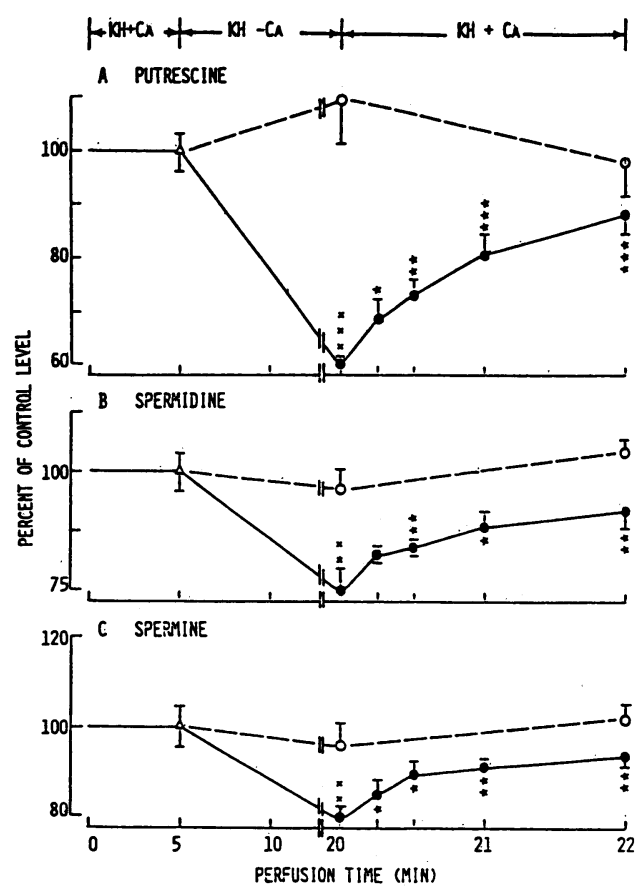

Figure 2. Effect of euthermic and hypothermic calcium-free perfusion and calcium reperfusion on heart polyamine levels. Data are from hearts used to generate Fig. 1 and are means $\pm \operatorname{SEM}(n=6$ hearts per treatment group). Control perfusion values (open triangle, $100 \%$ on the ordinate, in $\mathrm{pmol} / \mathrm{mg}$ protein): putrescine, $120 \pm 4$; spermidine, $700 \pm 25$; spermine, $1,740 \pm 70 .{ }^{\times} P<0.01,{ }^{\times \times \times} P<0.001$ vs. control perfusion. ${ }^{*} P<0.05,{ }^{* *} P<0.01,{ }^{* * *} P<0.001$ vs. calciumfree perfusion value at $20 \mathrm{~min}$ ). calcium paradox, we monitored the mechanical performance of the perfused heart with a strain gauge. In the standard protocol, the heart stopped beating during calcium-free perfusion; calcium reperfusion of the quiescent, calcium-depleted heart failed to restore spontaneous contraction (Fig. $3 \mathrm{~A}$ ). The addition of $5 \mathrm{mM}$ DFMO to all perfusion media, or $10 \mathrm{mM}$ DFMO for the last 2 min of calcium-free perfusion and first 2 min of calcium reperfusion (not shown), allowed almost immediate resumption of near normal contractility after readmission of calcium-containing $\mathrm{KH}$ buffer (Fig. $3 \mathrm{~B}$ ). Putrescine $(0.5-1$ $\mathrm{mM}$ ) added to DFMO-containing perfusion media negated DFMO protection and prevented the return of contractility during calcium reperfusion (Fig. $3 C$ ). In control experiments with hearts not subjected to calcium-free perfusion, perfusion with $5 \mathrm{mM}$ DFMO or $0.5 \mathrm{mM}$ putrescine was well tolerated for $10-15 \mathrm{~min}$.

Release of cytosolic constituents. Heart cell damage was monitored biochemically by measuring the release of soluble cytosolic markers into the coronary effluent. Little or no release of cytosolic constituents occurred during perfusion with $\mathrm{KH}$ medium and with calcium-free $\mathrm{KH}$ medium. Calcium reperfusion after 5 or $15 \mathrm{~min}$ of calcium-free perfusion caused a major efflux of creatine kinase, lactate dehydrogenase, and glutamate-oxaloacetate transaminase at $2 \mathrm{~min}$ (Fig. 4). This efflux was substantially suppressed by $5 \mathrm{mM}$ DFMO. In the kinetic study shown in Fig. 5, a significant release of myoglobin and cellular protein was detectable between 20 and $40 \mathrm{~s}$ after initiating calcium reperfusion, and this release progressed for at least $2 \mathrm{~min}$. $5 \mathrm{mM}$ DFMO blocked the reperfusion-induced release of myoglobin and protein, whereas putrescine nullified DFMO inhibition and enhanced the efflux of these constituents. Further, putrescine augmented the release of myoglobin and protein in the absence of DFMO (Table III). The addition of $10 \mathrm{mM}$ DFMO for the last $2 \mathrm{~min}$ of calciumfree perfusion and the first 2 min of calcium reperfusion also inhibited the release of myoglobin and protein (Table IV). In control perfusions of hearts not subjected to calcium depletion, DFMO (data not shown) and putrescine (Table III) were without effect on the efflux of cytosolic markers.

${ }^{45} \mathrm{Ca}$ uptake. ${ }^{45} \mathrm{Ca}$ perfusion was followed by a cold washout for $15 \mathrm{~min}$ at $0^{\circ} \mathrm{C}$ with calcium-free $\mathrm{KH}$ medium containing $0.5 \mathrm{mM}$ EGTA to remove ${ }^{45} \mathrm{Ca}$ from the vascular and extracellular compartments and allow measurement of intracellular ${ }^{45} \mathrm{Ca}$. This cold washout of ${ }^{45} \mathrm{Ca}$ reached asymptote and removed $>99 \%$ of the total ${ }^{45} \mathrm{Ca}$ in control perfusions, indicating that the great bulk of the ${ }^{45} \mathrm{Ca}$ was present in the extracellular and vascular compartments. In the experiments shown in Fig. 6, calcium reperfusion induced a 22- and 17-fold increase in cellular ${ }^{45} \mathrm{Ca}$ influx at $15 \mathrm{~s}$ and $2 \mathrm{~min}$. DFMO inhibited the calcium reperfusion-induced increase in cellular ${ }^{45} \mathrm{Ca}$ influx by $80 \%$, and the release of myoglobin and protein (at $2 \mathrm{~min}$ ) by $89 \%$ and $79 \%$ (not shown). Putrescine negated DFMO inhibition and enhanced ${ }^{45} \mathrm{Ca}^{2+}$ influx and release of myoglobin and protein (not shown) at 2 min (Fig. 6). Putrescine also enhanced the calcium reperfusion-induced increment in ${ }^{45} \mathrm{Ca}$ influx and release of myoglobin and protein in the absence of DFMO, whereas it was without effect on these parameters in control hearts not subjected to calcium-free perfusion (Table III). The addition of $10 \mathrm{mM}$ DFMO for the last $2 \mathrm{~min}$ of calcium-free perfusion and the first $2 \mathrm{~min}$ of calcium reperfusion inhibited cellular ${ }^{45} \mathrm{Ca}$ influx by $68 \%$ during a 5-min reperfusion, and putrescine nullified DFMO inhi- 
Table I. Rapid Effect of Calcium Depletion on Heart ODC Activity and Polyamine Levels

\begin{tabular}{lllll}
\hline & ODC & Putrescine & Spermidine & Spermine \\
\hline & pmol/h per $m$ g protein & $n$ mol/mg protein & $n$ nmol/mg protein & $n$ nol/mg protein \\
Control perfusion & $579 \pm 57$ & $0.102 \pm 0.010$ & $0.406 \pm 0.026$ & $0.84 \pm 0.055$ \\
Ca-free perfusion & $329 \pm 28^{*}$ & $0.064 \pm 0.002^{*}$ & $0.246 \pm 0.02^{*}$ & $0.52 \pm 0.029^{*}$ \\
\% of control & 56.8 & 61.7 & 60.6 & 61.9 \\
\hline
\end{tabular}

Control perfusion was for $10 \mathrm{~min}$ with normal $\mathrm{KH}$ buffer (containing $2.5 \mathrm{mM} \mathrm{Ca}$ ). Calcium-free perfusions were for $5 \mathrm{~min}$ with normal $\mathrm{KH}$ buffer and $5 \mathrm{~min}$ with calcium-free $\mathrm{KH}$ buffer containing $50 \mu \mathrm{M}$ EGTA. Hearts were freeze-clamped immediately after these perfusions. Data are means $\pm \operatorname{SEM}(n=12$ hearts). $* P<0.001$ vs. control.

bition (Table IV). These data are consistent with the view that DFMO and putrescine exert their effects during calcium reperfusion.

Morphological changes. The fine structure of ventricular myocytes in control hearts perfused with $\mathrm{KH}$ medium (Fig. 7 $A$ ) was similar to that of hearts fixed in situ by vascular perfusion. Calcium reperfusion caused extensive cellular damage manifested by a widespread occurrence of contracture bands, contracted fibers, and discharging mitochondria at intercalated discs in myocardial cells (Fig. 7 B). 5 mM DFMO attenuated the development of the calcium reperfusion-induced changes in myocardial cell structure (Fig. $7 C$ ), whereas 0.5 $\mathrm{mM}$ putrescine nullified DFMO protection (Fig. $7 \mathrm{D}$ ). Quantitative assessment of morphological damage at the light microscopic level showed that DFMO reduced the percentage of severely damaged myocytes by $71 \%$ after $5 \mathrm{~min}$ of calcium repletion (Table V). Putrescine negated DFMO inhibition and significantly increased the percentage of damaged myocytes (Table V).

Hypothermia. Hypothermia is known to attenuate or prevent the calcium paradox, with nearly complete protection from $5 \mathrm{~min}$ of calcium-free perfusion being afforded by reduction of the temperature during calcium-free perfusion to $22^{\circ} \mathrm{C}$ $(30,31)$. We therefore investigated the impact of hypothermia on heart ODC and polyamine levels in the calcium paradox. As expected, calcium-free perfusion at $18^{\circ} \mathrm{C}$ for 15 min protected the heart against calcium reperfusion-induced loss of contractility and release of myoglobin and protein (data not shown). Likewise, calcium-free perfusion at $18^{\circ} \mathrm{C}$ for $15 \mathrm{~min}$ caused no change in heart ODC (Fig. 1) or polyamine levels (Fig. 2). Moreover, calcium reperfusion at $37^{\circ} \mathrm{C}$ after calcium depletion at $18^{\circ} \mathrm{C}$ also had no effect on heart ODC (Fig. 1) or polyamines (Fig. 2).

\section{Discussion}

This investigation shows for the first time that the development of the calcium paradox is associated with rapid changes in heart ODC activity and polyamine levels. Calcium-free perfusion induces an early ( $<5 \mathrm{~min}$ ) decrease in myocardial ODC activity. This is associated with a reduction in the concentration of polyamines that is not attributable to their extracellular release. The subsequent reintroduction of $\mathrm{Ca}^{2+}$ evokes an acute $(<15 \mathrm{~s})$ rise in heart ODC activity and prompt $(<15-30$ s) sequential increments in polyamines in the order of putrescine $>$ spermidine $>$ spermine during 120 s of calcium reperfusion. This rank order is consistent with the precursor-product relationship seen in the ODC-mediated pathway for polyamine synthesis (10-12). Direct support for this synthetic pathway comes from the finding that the specific ODC inhibitor DFMO (29) blocks the calcium reperfusion-induced increase in polyamines.

For polyamines to qualify as mediators of abnormal $\mathrm{Ca}^{2+}$ influx leading to the calcium paradox, the following criteria should be met. (a) The calcium repletion-induced stimulation of ODC activity and polyamine accumulation should com-

Table II. Effect of DFMO and Putrescine on Calcium Repletion-induced Changes in Heart ODC and Polyamines

\begin{tabular}{|c|c|c|c|c|}
\hline \multirow[b]{2}{*}{ Treatment } & \multirow[b]{2}{*}{ ODC activity } & \multicolumn{3}{|c|}{ Polyamine concentration } \\
\hline & & Putrescine & Spermidine & Spermine \\
\hline & pmol/h per mg protein & nmol/mg protein & nmol/mg protein & nmol/mg protein \\
\hline Control perfusion & $595 \pm 95^{*}$ & $0.112 \pm 0.01^{*}$ & $0.55 \pm 0.08^{*}$ & $0.91 \pm 0.12^{*}$ \\
\hline Ca-free perfusion & $292 \pm 11$ & $0.068 \pm 0.01$ & $0.29 \pm 0.02$ & $0.56 \pm 0.04$ \\
\hline Ca reperfusion & $570 \pm 68^{\ddagger}$ & $0.106 \pm 0.01^{*}$ & $0.44 \pm 0.06^{\ddagger}$ & $0.79 \pm 0.06^{*}$ \\
\hline Ca reperfusion + DFMO & $335 \pm 59^{\S}$ & $0.073 \pm 0.01^{\S}$ & $0.24 \pm 0.01^{\prime \prime}$ & $0.49 \pm 0.01^{\prime \prime}$ \\
\hline Ca reperfusion + DFMO + putrescine & $556 \pm 48^{\prime}$ & $1.21 \pm 0.10^{* *}$ & $0.37 \pm 0.02^{\prime}$ & $0.67 \pm 0.04^{\text {}}$ \\
\hline
\end{tabular}

Control perfusions were for $10 \mathrm{~min}$ with normal $\mathrm{KH}$ buffer containing $2.5 \mathrm{mM} \mathrm{Ca}$. Calcium-free perfusions were for $5 \mathrm{~min}$ with normal buffer and $5 \mathrm{~min}$ with calcium-free $\mathrm{KH}$ buffer (containing $50 \mu \mathrm{M}$ EGTA). Calcium reperfusions consisted of a perfusion sequence of normal KH buffer for $5 \mathrm{~min}$, calcium-free $\mathrm{KH}$ buffer for $5 \mathrm{~min}$, and $\mathrm{KH}$ buffer containing $2.5 \mathrm{mM} \mathrm{Ca}$ for $5 \mathrm{~min}$. $5 \mathrm{mM}$ DFMO without or with $0.5 \mathrm{mM}$ putrescine was added to normal and calcium-free $\mathrm{KH}$ buffer, and hearts were perfused in the same manner as in calcium reperfusions. The results are means $\pm \operatorname{SEM}\left(n=3\right.$ hearts per treatment group). ${ }^{*} P<0.05,{ }^{\ddagger} P<0.01$ vs. calcium-free perfusion. ${ }^{\S} P<0.05$, $" P<0.01$ vs. calcium reperfusion. ${ }^{T} P<0.05,{ }^{* *} P<0.001,{ }^{\sharp} P<0.01$ vs. calcium reperfusion + DFMO. 


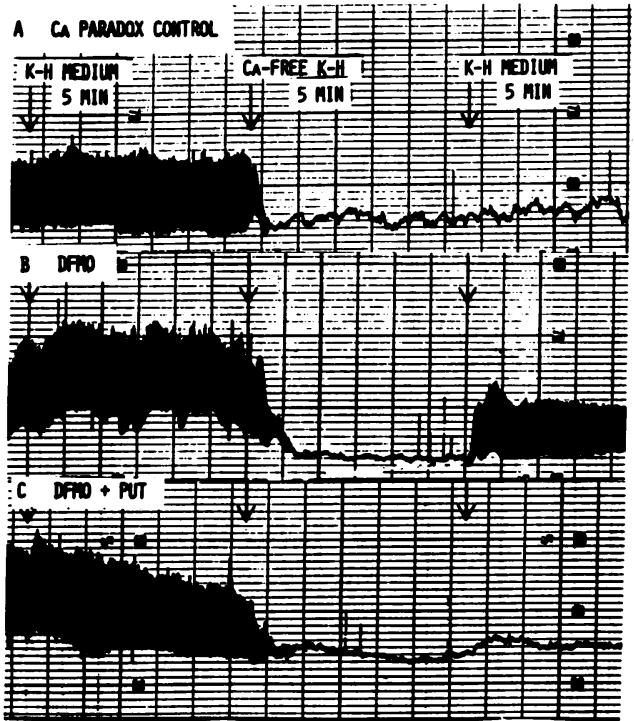

Figure 3. DFMO blocks the loss of cardiac contractility induced by calcium reperfusion, and putrescine nullifies the DFMO effect. Hearts were perfused as described in Table II. Cardiac contractility was monitored by myography with a force-displacement transducer. Similar results were obtained in at least 10 separate experiments. $(A)$ Calcium reperfusion after calcium-free perfusion failed to restore spontaneous cardiac contraction (calcium paradox). (B) $5 \mathrm{mM}$ DFMO added to all perfusion media allowed the restoration of near normal cardiac contractility after calcium reperfusion. (C) $0.5 \mathrm{mM}$ putrescine blocked the DFMO effect and restored the calcium repletion-induced loss of cardiac contractility.

mence before or coincident with the onset of abnormal $\mathrm{Ca}^{2+}$ influx, and be followed by cellular injury. (b) Blockade of ODC-mediated polyamine synthesis should suppress enhanced $\mathrm{Ca}^{2+}$ influx and prevent the calcium paradox. (c) Exogenous putrescine, the product of ODC activity, should replenish cellular polyamines and nullify the effects of ODC inhibition.

The calcium paradox is characterized by a sudden, explosive onset with a measurable gain in heart calcium within $15 \mathrm{~s}$ (8), followed by contracture and transition to irreversible injury within $30 \mathrm{~s}$ of calcium reperfusion (32). We have demonstrated significant increases in the levels of heart ODC, putrescine, and spermidine, and enhanced cellular ${ }^{45} \mathrm{Ca}^{2+}$ influx within $15 \mathrm{~s}$ of calcium repletion, the earliest time point examined. Significant cellular damage, as monitored by myoglobin release, is observed by $30-40 \mathrm{~s}$, and becomes maximal between 60 and $120 \mathrm{~s}$ of $\mathrm{Ca}^{2+}$ calcium reperfusion. Thus the kinetics of these changes appear to be consistent with the hypothesis that polyamines serve as mediators of abnormal $\mathrm{Ca}^{2+}$ influx leading to the calcium paradox.

We used DFMO as a molecular probe to directly assess the pathophysiological role of polyamines in the calcium paradox. DFMO is a specific, enzyme-activated, irreversible inhibitor of ODC (29) which has no other known biological action, although in longer-term experiments it results in adaptive changes to putrescine depletion, including increases in $s$-adenosylmethionine decarboxylase and polyamine oxidase activities and decarboxylated s-adenosylmethione levels (12). DFMO has been extensively used to deplete cellular polyamines and delineate polyamine-dependent processes (10-12). DFMO effectively suppressed the calcium reperfusion-induced stimulation of heart ODC activity and the increase in polyamines, and coincidentally attenuated or blocked cellular ${ }^{45} \mathrm{Ca}$ influx, contractile failure, loss of cytosolic constituents, and structural lesions. Conversely putrescine, the product of ODC activity, replenished cellular polyamines and nullified DFMO protection, allowing the full development of the calcium paradox. Indeed in some experiments (Table V, Figs. 4 and 6) putrescine significantly intensified certain manifestations of the calcium paradox in the DFMO-treated heart. Moreover, putrescine has been found to accelerate the uncontrolled entry of extracellular $\mathrm{Ca}^{2+}$ and development of the calcium paradox in the absence of DFMO (Table III). It is noteworthy that exogenous putrescine apparently protected heart ODC from DFMO inhibition in these short-term experiments (Table II). The mechanism for this protective action of putrescine is unknown but may involve putrescine competition with DFMO for a binding site on ODC, or inhibition of ODC decarboxylation of DFMO, an essential prerequisite for suicide inhibition of ODC (29), by putrescine (product inhibition). Thus putrescine could prevent DFMO inhibition of the evoked accumulation of cellular polyamines by two mechanisms: $(a)$ by protecting against DFMO inhibition of enhanced ODC activity; and/or $(b)$ by transport of putrescine into cells and its conversion to higher polyamines. These data show that rapid polyamine synthesis is obligatory for the mediation of calcium reperfusion-induced $\mathrm{Ca}^{2+}$ influx and cellular damage. Thus polyamines fully satisfy the criteria required of a mediator to trigger abnormal $\mathrm{Ca}^{2+}$ influx and precipitate the calcium paradox.

Independent evidence that polyamines play an essential role in the pathophysiology of the calcium paradox comes from our experiments on hypothermia. Calcium-free perfusion causes an early time- $(5,8)$ and temperature-dependent (5) reduction in heart calcium content, and calcium reperfusion induces an acute $(<15 \mathrm{~s})$ gain in heart calcium rising to
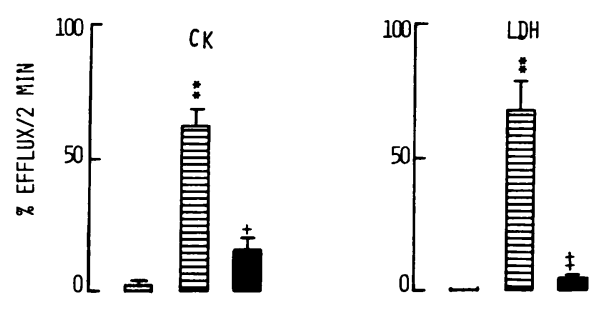

CALCIUM PERFUSION

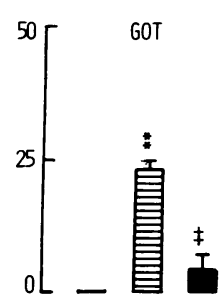

DFMD + CALCIUM PERFUSION
Figure 4. DFMO blocks the calcium reperfusion-induced release of heart enzymes. Hearts were perfused as described in Table II and in the text. Heart effluents were collected over a 2-min period of calcium reperfusion for enzyme assays. Control effluents were collected between 10 and 12 min of perfusion with $\mathrm{KH}$ medium. $C K$, creatine kinase; $L D H$, lactate dehydrogenase; $G O T$, glutamate-oxaloacetate transaminase. Data are expressed as percent of the total activity (perfusate + heart) and are means $\pm \operatorname{SEM}\left(n=3\right.$ hearts per treatment). ${ }^{* *} P<0.01$ vs. control. ${ }^{+} P<0.05,{ }^{\ddagger} 0.01$ vs. calcium reperfusion. 


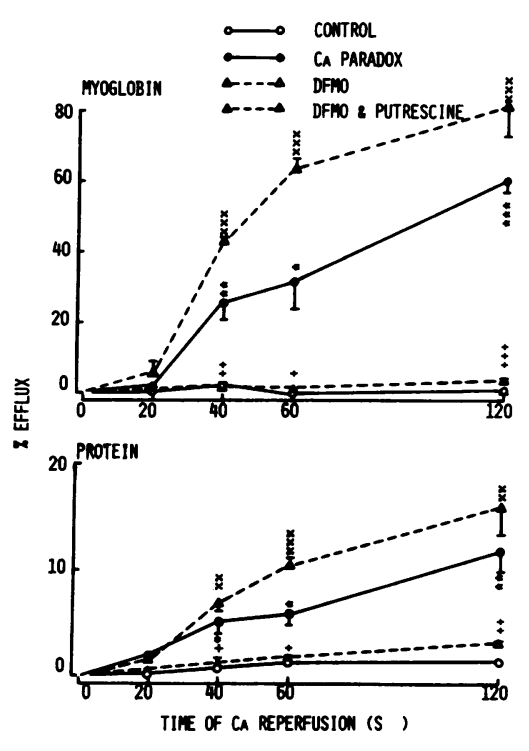

Figure 5. DFMO blocks the calcium reperfusion-induced release of heart myoglobin and protein, and putrescine negates the DFMO effect. Hearts were perfused as described in Table II. Heart effluents were collected at the given times and analyzed for myoglobin and protein. Data are means $\pm \operatorname{SEM}(n=3$ hearts per treatment). ${ }^{*}, * * P<0.05,0.01$ vs. control. ${ }^{+} P<0.05,{ }^{++} P$ $<0.01,{ }^{++} P<0.001$ vs. calcium reperfusion. ${ }^{x \times} P<0.01,{ }^{x \times \times} P$ $<0.001$ vs. DFMO $+\mathrm{Ca}$ reperfusion.

asymptote at $2 \mathrm{~min}(5,8)$. Hypothermia prevents calcium depletion (5) and concomitant loss of ODC and polyamines during calcium-free perfusion, as well as the calcium reperfusioninduced increase in ODC activity and polyamine levels and calcium overload $(5,30)$. These findings confirm that ODCmediated polyamine synthesis is involved in the mediation of abnormal $\mathrm{Ca}^{2+}$ influx and calcium overload in the calcium paradox. In addition, they suggest that calcium depletion-induced deactivation of ODC is a necessary prerequisite for the subsequent activation of ODC evoked by calcium reperfusion.

These findings focus attention on the role of $\mathrm{Ca}^{2+}$ in the regulation of ODC activity and polyamine synthesis in heart cells. Extracellular $\mathrm{Ca}^{2+}$ is required for the induction of ODC activity in cultured cells by a number of agonists. This induction is expressed after a delay of several hours and reflects transcriptional and/or translational regulation of de novo ODC synthesis (33-36). A direct role for $\mathrm{Ca}^{2+}$ in regulating

Table III. Effect of Putrescine on ${ }^{45}$ Ca Influx and Myoglobin Release During Control Perfusion and Calcium Reperfusion

\begin{tabular}{|c|c|c|}
\hline Treatment & ${ }^{45} \mathrm{Ca}$ uptake & Myoglobin release \\
\hline & nmol/mg protein & $\%$ total/1 min \\
\hline Control perfusion & $0.42 \pm 0.03$ & $0.4 \pm 0.05$ \\
\hline $\begin{array}{l}\text { Control perfusion }+1 \mathrm{mM} \\
\text { putrescine }\end{array}$ & $031+0.06$ & $2+0.5$ \\
\hline Calcium reperfusion & $8.67 \pm 2.0^{*}$ & $55.1 \pm 7.5^{\ddagger}$ \\
\hline $\begin{array}{l}\text { Calcium reperfusion }+1 \mathrm{mM} \\
\text { putrescine }\end{array}$ & $17.95 \pm 0.32^{8}$ & $84 \pm 16^{8}$ \\
\hline
\end{tabular}

Hearts were perfused for $5 \mathrm{~min}$ with $\mathrm{KH}$ buffer, $5 \mathrm{~min}$ with calciumfree $\mathrm{KH}$ buffer, and then reperfused with ${ }^{45} \mathrm{Ca}(1 \mu \mathrm{Ci} / \mathrm{ml})$ in calciumcontaining $\mathrm{Kh}$ for $1 \mathrm{~min}$ followed by a 15 -min washout at $0^{\circ} \mathrm{C}$ with calcium-free $\mathrm{KH}$ containing $0.5 \mathrm{mM}$ EGTA. The myoglobin in the coronary effluents collected during the 1-min calcium reperfusion and the 15-min cold washout were combined for this table. Data are means $\pm \operatorname{SEM}(n=3$ or 4 hearts per treatment group).

${ }^{*} P<0.01,{ }^{\ddagger} P<0.001$ vs. control perfusion.

${ }^{8} P<0.05$ vs. calcium reperfusion.
Table IV. Effect of Restricted Use of DFMO and Putrescine on Cellular ${ }^{45} \mathrm{Ca}$ Influx and Myoglobin Release Induced by Calcium Reperfusion

\begin{tabular}{llc}
\hline Treatment & ${ }^{45} \mathrm{Ca}$ uptake & Myoglobin release \\
\hline & nmol/mg protein & \% total/5 min \\
& $0.23 \pm 0.02$ & $1.1 \pm 0.8$ \\
$\begin{array}{l}\text { Control perfusion } \\
\text { Calcium reperfusion }\end{array}$ & $7.30 \pm 0.54^{*}$ & $92.4 \pm 0.67^{*}$ \\
$\begin{array}{l}\text { Calcium reperfusion }+10 \mathrm{mM} \\
\quad \text { DFMO }\end{array}$ & $2.68 \pm 0.37^{\dagger}$ & $23.6 \pm 2.1^{8}$ \\
$\begin{array}{l}\text { Calcium reperfusion }+10 \mathrm{mM} \\
\text { DFMO }+1 \mathrm{mM} \text { putrescine }\end{array}$ & $8.37 \pm 1.12^{11}$ & $84.8 \pm 7.9^{11}$ \\
\hline
\end{tabular}

Hearts were perfused for $5 \mathrm{~min}$ with $\mathrm{KH}$ buffer, $5 \mathrm{~min}$ with calciumfree $\mathrm{KH}$ buffer, and then reperfused with ${ }^{45} \mathrm{Ca}(1 \mu \mathrm{Ci} / \mathrm{ml})$ in calciumcontaining $\mathrm{KH}$ buffer for $5 \mathrm{~min}$ followed by a 15 -min washout at $0^{\circ} \mathrm{C}$ with calcium-free $\mathrm{KH}$ buffer containing $0.5 \mathrm{mM}$ EGTA. $10 \mathrm{mM}$ DFMO without and with $1 \mathrm{mM}$ putrescine was present during the last $2 \mathrm{~min}$ of calcium-free perfusion and first $2 \mathrm{~min}$ of calcium reperfusion. Results are means $\pm \operatorname{SEM}$ ( $n=4$ hearts per treatment group).

$* P<0.001$ vs. control perfusion.

${ }^{\ddagger} P<0.01,{ }^{8} P<0.001$ vs. calcium reperfusion.

" $P<0.01$ vs. calcium reperfusion + DFMO.

ODC induction is supported by observations in cultured epithelial cells indicating that sequential calcium depletion and repletion induce a decrease followed by an increase in ODC

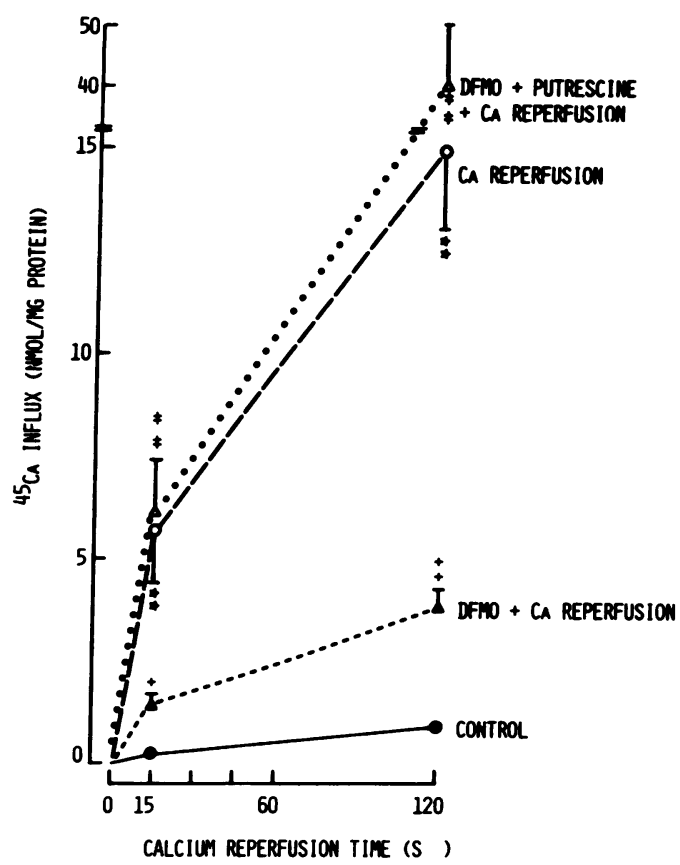

Figure 6. DFMO attenuates abnormal cellular ${ }^{45} \mathrm{Ca}^{2+}$ influx induced by calcium reperfusion and putrescine negates the DFMO effect. Hearts were perfused as described in Table II except that calcium reperfusion was for 15 or $120 \mathrm{~s}$ with ${ }^{45} \mathrm{Ca}(1 \mu \mathrm{Ci} / \mathrm{ml})$ in $\mathrm{KH}$ buffer, followed by a 15-min cold washout with calcium-free $\mathrm{KH}$ buffer containing $0.5 \mathrm{mM}$ EGTA. $10 \mathrm{mM}$ DFMO without or with $1 \mathrm{mM}$ putrescine was added to normal and calcium-free $\mathrm{KH}$ buffer. Data are means $\pm \operatorname{SEM}\left(n=3-4\right.$ hearts per treatment group). ${ }^{* *} P<0.01$ vs. control. ${ }^{+} P<0.05,{ }^{++} P<0.01$ vs. Ca reperfusion. ${ }^{\ddagger \neq} P<0.01$ vs. DFMO + Ca reperfusion. 

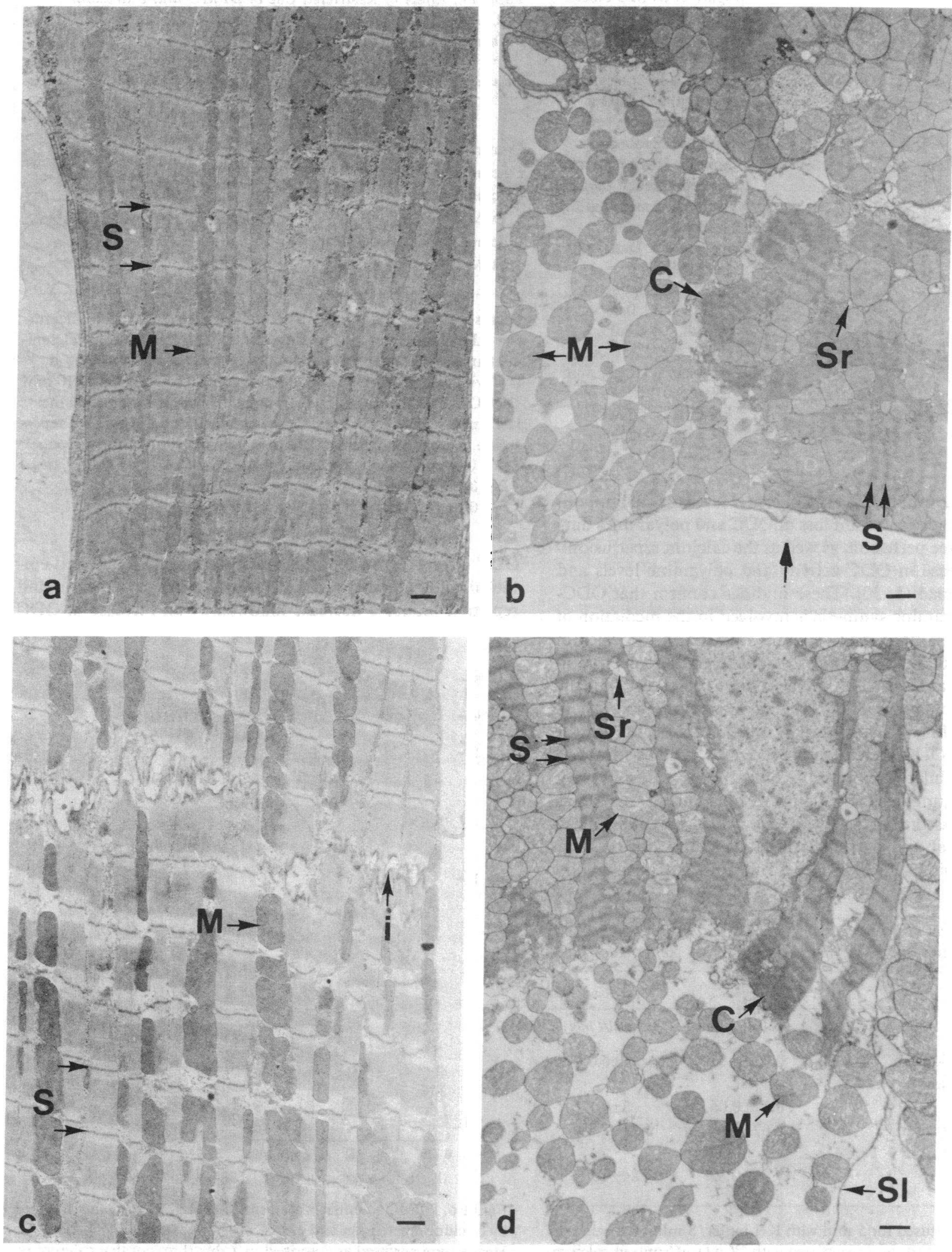

Figure 7. DFMO protects against the ultrastructural damage induced in ventricular myocytes by calcium reperfusion, and putrescine negates DFMO protection. The experimental protocol is the same as that described in Table II. Electron micrographs are magnified 4,800 $\times$. Calibration bar, $1 \mu \mathrm{m}$. $S$, sarcomere; $M$, mitochondrion; $i$, intercalated disc; $C$, contracture band; $S r$, sarcoplasmic reticulum; $S l$, sarcolemma. (a) Control heart perfused with calcium-containing $\mathrm{KH}$

medium. Normal morphology with compact mitochondria and well defined, normally spaced and aligned sarcomeres. $(b)$ Calcium reperfusion for $5 \mathrm{~min}$. Morphological changes include mitochondrial swelling, ejection of mitochondria into myofiber terminals, contracture bands, shortening of sacomeres, and apparent swelling of the sarcoplasmic reticulum. The sarcolemma appears intact. (c) Calcium-reperfused heart treated with DFMO. Note generally intact 
Table V. Effect of DFMO and Putrescine on Percent of Damaged Myocytes after 5 Min of Calcium Reperfusion

\begin{tabular}{lc}
\hline Treatment & Damaged myocytes \\
\hline & $\%$ \\
Control perfusion & $3.0 \pm 1.7$ \\
Calcium reperfusion & $57.0 \pm 1.3^{*}$ \\
Calcium reperfusion + 5 mM DFMO & $19.7 \pm 6.4^{\ddagger}$ \\
Calcium reperfusion $\pm 5 \mathrm{mM}$ DFMO $+0.5 \mathrm{mM}$ & \\
$\quad$ putrescine & $98.4 \pm 0.4^{\S}$ \\
\hline
\end{tabular}

Hearts were perfused according to the protocol described in Table II. Each result represents the mean \pm SEM of data obtained from four rat hearts per treatment group as described in Methods.

$* P<0.001$ vs. control perfusion.

${ }^{\ddagger} P<0.001$ vs. calcium reperfusion.

${ }^{8} P<0.001$ vs. calcium reperfusion +5 mM DFMO.

activity after a lag period of $2-4 \mathrm{~h}$ in each state (37). However, there appears to be no precedent in any in vitro eukaryotic system for either the rapid decline in ODC activity and polyamine concentrations induced by calcium depletion or the abrupt rise in ODC activity and polyamine concentrations evoked by calcium repletion. Our findings in the calcium paradox strongly suggest that in cardiac myocytes ODC is a $\mathrm{Ca}^{2+}$ sensitive enzyme, i.e., its catalytic activity is regulated by the $\mathrm{Ca}^{2+}$ concentration, under conditions of low extracellular $\mathrm{Ca}^{2+}$ $(<50 \mu \mathrm{M})$. These changes in ODC activity are too rapid to be mediated by a transcriptional or translational regulation of ODC synthesis, and hence probably represent a deactivationreactivation sequence involving a preexisting ODC by a posttranslational mechanism.

We have previously hypothesized that ODC activity is normally regulated by depolarizing and receptor-operated signals via a molecular cascade involving $\mathrm{Ca}^{2+}, \mathrm{Ca}^{2+}$ channels, calmodulin, phospholipases, prostaglandins, cAMP, and the cytoskeleton $(13,14,16,17,20,21)$. This cascade induces a rapid; transient activation of a cryptic ODC associated with the plasmalemma (sarcolemma) through a posttranslational change that may involve a reversible phosphorylation-dephosphorylation sequence of ODC, an ODC-regulatory protein, or an ODC binding site. We now hypothesize that during calcium depletion, sarcolemmal ODC becomes $\mathrm{Ca}^{2+}$-sensitive and its catalytic activity is then regulated via one or more $\mathrm{Ca}^{2+}-$ or $\mathrm{Ca}^{2+}$-calmodulin-dependent, rate-regulatory reactions in this molecular cascade. This cascade may be temperature-dependent, as ODC deactivation fails to occur if calcium-free perfusion is conducted under hypothermal conditions $\left(18^{\circ} \mathrm{C}\right)$. The rapid reduction in polyamines during calcium-free perfusion apparently reflects an abrupt decline in ODC-mediated polyamine synthesis and a concomitant rapid degradation of heart polyamines under these conditions, inasmuch as extracellular release of polyamines has been ruled out.

The calcium reperfusion-induced elevation of ODC and polyamine levels resembles that induced by physiological concentrations of hormones with respect to time course, magnitude, and DFMO sensitivity (13-21). In contrast, calcium reperfusion increases ${ }^{45} \mathrm{Ca}^{2+}$ influx dramatically (17- to 22-fold), whereas hormonal stimulation of ${ }^{45} \mathrm{Ca}^{2+}$ influx is of much smaller magnitude (1.5- to 3-fold) $(13,14,20$; Fan, C. C., and H. Koenig. Polyamines mediate $\beta$-adrenergic stimulation of calcium fluxes and membrane transport in rat heart. Submitted for publication). Apparently the calcium depletion-mediated decline in ODC activity and polyamine levels "primes" heart cells for the uncontrolled entry of $\mathrm{Ca}^{2+}$ induced by calcium reperfusion. Recent investigations have implicated physiological pathways, primarily $\mathrm{Na}^{+} / \mathrm{Ca}^{2+}$ exchange, and to a lesser extent voltage-sensitive $\mathrm{Ca}^{2+}$ channels, for this abnormal $\mathrm{Ca}^{2+}$ entry (6-8, 32, 38-41). In light of the polyamine dependence of the $\mathrm{Ca}^{2+}$ influx evoked by calcium reperfusion, as well as by hormonal stimulation (13-21), it is likely that $\mathrm{Na}^{+} / \mathrm{Ca}^{2+}$ exchange and $\mathrm{Ca}^{2+}$ channel activity involve one or more polyamine-dependent, rate-regulatory steps. Possible molecular mechanisms by which polyamines could regulate transmembrane $\mathrm{Ca}^{2+}$ movements include any of the following modifications of ion channel, pump, or transporter molecules: $(a)$ phosphorylations and dephosphrylations by polyamine-sensitive protein kinases and phosphatases; $(b)$ polyamines binding to anionic sites and acting as counterions to decrease surface change and surface potential: $(c)$ polyamines displacing bound calcium by a cation-exchange reaction.

Our experimental data are consistent with the following model for intracellular $\mathrm{Ca}^{2+}$ overload in the calcium paradox. In this hypothetical model heart myocytes subjected to calcium-free perfusion are rendered $\mathrm{Ca}^{2+}$-intolerant because calcium depletion $(5,8)$ and the accompanying polyamine depletion cause $\mathrm{Na}^{+} / \mathrm{Ca}^{2+}$ exchange and $\mathrm{Ca}^{2+}$ channel activity to become supersensitive to polyamines. Small amounts of polyamines synthesized by $\mathrm{Ca}^{2+}$-activated ODC within seconds after readmission of calcium would cause a rapid massive entry of extracellular $\mathrm{Ca}^{2+}$. In addition, an impaired capacity of calcium-depleted cells to regulate internal $\mathrm{Ca}^{2+}$ by sequestration in the sarcoplasmic reticulum $(42,43)$ and extrusion across the sarcolemma $(43,44)$ via their respective $\mathrm{Ca}^{2+}$ -ATPase pumps has been implicated in the phenomenon of $\mathrm{Ca}^{2+}$-intolerance, and polyamines could contribute to this mechanism. The resulting rise in free myoplasmic and intramitochondrial $\mathrm{Ca}^{2+}$ concentration would cause $(a)$ a loss of contraction, contracture, and cellular ATP depletion resulting from $\mathrm{Ca}^{2+}$ activation of myosin ATPase, and $(b)$ uncoupling of mitochondrial oxidative phosphorylation and consequent failure of ATP generation $(6,45)$. Other events associated with the calcium paradox, e.g., massive release of myoplasmic constituents and nonspecific increase in permeability through damaged sarcolemma and disrupted intercalated discs, apparently are secondary events developing after, and partly as a consequence of, contracture and transition to irreversible injury at $\sim 20-30 \mathrm{~s}(32,46)$.

These experiments raise a number of important questions regarding the calcium paradox which remain to be addressed structure, including compact mitochondria, and slightly lengthened sarcomeres and partially separated intercalated discs associated with calcium-free perfusion. (d) Calcium reperfused heart treated with DFMO and putrescine. Cellular damage is similar to that in un- treated calcium-reperfused heart shown in $(b)$. Note the shortening of sarcomeres, apparent swelling of sarcoplasmic reticulum, swelling and terminal ejection of mitochondria, contracture bands, and intact sarcolemma. 
in future studies. These include the cellular and molecular mechanisms underlying the short-term regulation of ODC activity and polyamine synthesis by $\mathrm{Ca}^{2+}$, the control of transmembrane $\mathrm{Ca}^{2+}$ movements by polyamines, and the mediation of cell damage. Our findings raise the interesting possibility that similar changes in ODC activity and polyamine synthesis may be involved in other pathophysiological states associated with intracellular $\mathrm{Ca}^{2+}$ overload. If this inference is confirmed, DFMO and other interventions that attenuate polyamine synthesis may prove to be of value in their treatment.

\section{Acknowledgments}

We thank Dr. C.-C. Fan for biochemical assistance in the initial phases of this study, Mr. P. Joshi for electron microscopic assistance, and Mrs. T. Howell for the secretarial work.

This work was supported by the Veterans Administration Research Service and National Institutes of Health grants HL-26835 and NS-18047. Merrell-Dow Research Center (Cincinnati, OH) generously provided $\alpha$-DFMO

\section{References}

1. Chapman, R. A. 1983. Control of cardiac contractility at the cellular level. Am. J. Physiol. 245:H535-H552.

2. Fabiato, A. 1979. Calcium and cardiac excitation-contraction coupling. Annu. Rev. Physiol. 41:473-484.

3. Frank, J. S., T. L. Rich, S. Beydler, and M. Kreman. 1983 Calcium depletion in rabbit myocardium. Ultrastructure of the sarcolemma and correlation with the calcium paradox. Circ. Res. 51:117130.

4. Zimmerman, A. N. E., and W. C. Hulsmann. 1966. Paradoxical influence of calcium ions on the permeability of the cell membrane in isolated rat hearts. Nature (Lond.). 211:646-647.

5. Alto, L. E., and N. S. Dhalla. 1979. Myocardial cation contents during induction of the calcium paradox. Am. J. Physiol. 327:H713H719.

6. Grinwald, P. M., and W. G. Nayler. 1981. Calcium entry in the calcium paradox. J. Mol. Cell. Cardiol. 13:867-881.

7. Nayler, W. G., E. J. S. Perry, and M. J. Daly. 1983. The biochemistry of uncontrolled calcium entry. Eur. Heart J. 4(Suppl. H):29-41.

8. Nayler, W. G., S. E. Perry, J. S. Pelz, and M. J. Daly. 1984. Calcium, sodium and the calcium paradox. Circ. Res. 55:227-237.

9. Flamigni, F., C. Rossoni, C. Stafanelli, and C. M. Caldarera. 1986. Polyamine metabolism and function in the heart. J. Mol. Cell. Cardiol. 18:3-11.

10. Heby, O. 1981. Role of polyamines in the control of cell proliferation and differentiation. Differentiation. 19:1-20.

11. Tabor, C. W., and H. Tabor. 1984. Polyamines. Annu. Rev. Biochem. 53:749-790.

12. Pegg, A. E. 1986. Recent advances in the biochemistry of polyamines in eukaryotes. Biochem. J. 234:249-262.

13. Koenig, H., A. Goldstone, and C. Y. Lu. 1983. Polyamines regulate calcium fluxes in a rapid plasma membrane response. Nature (Lond.). 305:530-534.

14. Koenig, H., A. D. Goldstone, and C. Y. Lu. 1983. $\beta$-Adrenergic stimulation of $\mathrm{Ca}^{2+}$ fluxes, endocytosis, hexose transport and amino acid transport in mouse kidney cortex is mediated by polyamine synthesis. Proc. Natl. Acad. Sci. USA. 80:7210-7214.

15. Fan, C.-C., and H. Koenig. 1984. $\beta$-Adrenergic stimulation of calcium fluxes and membrane transport processes in rat heart is mediated by polyamines. Fed. Proc. 43:735. (Abstr.)

16. Goldstone, A., H. Koenig, and C. Y. Lu. 1984. Triiodothyronine $\left(\mathrm{T}_{3}\right)$ stimulation of $\mathrm{Ca}^{2+}$ influx and membrane transport processes in mouse kidney cortex is mediated by polyamines. Fed. Proc. 43:735. (Abstr.)
17. Koenig, H., C.-C. Fan, and Z. Iqbal. 1984. Polyamines mediate $\mathrm{T}_{3}$ stimulation of $\mathrm{Ca}^{2+}$ and membrane transport. Trans. Am. Soc. Neurochem. 15:220. (Abstr.)

18. Goldstone, A., H. Koenig, and C. Y. Lu. 1985. Insulin stimulation of $\mathrm{Ca}^{2+}$ fluxes and membrane transport processes in mouse kidney cortex is mediated by polyamine synthesis. Fed. Proc. 44:1593. (Abstr.)

19. Goldstone, A. D., H. Koenig, and C. Y. Lu. 1986. Polyamines as mediators of insulin's action on pyruvate dehydrogenase, ${ }^{45} \mathrm{Ca}^{2+}$ fluxes, and membrane transport. Fed. Proc. 45:1011. (Abstr.)

20. Iqbal, Z., and H. Koenig. 1985. Polyamines appear to be second messengers in mediating $\mathrm{Ca}^{2+}$ fluxes and neurotransmitter release in potassium-depolarized synaptosomes. Biochem. Biophys. Res. Commun. 133:563-573.

21. Koenig, H., A. D. Goldstone, Z. Iqbal, C.-C. Fan, C. Y. Lu, and J. J. Trout. 1985. Polyamine synthesis plays a key role in the mediation of receptor- and voltage-regulated calcium fluxes. In Recent Progress in Polyamine Research. L. Selmeci, M. E. Brosnan, and N. Seiler, editors. Akademiai Kiadò, Budapest, Hungary. 191-201.

22. Gøtzsche, O. 1983. Decreased myocardial calcium uptake after isoproterenol in streptozotocin-induced diabetic rat. Studies in the in vitro perfused heart. Lab. Invest. 48:156-161.

23. Hunter, D. R., R. A. Haworth, and H. A. Berkoff. 1981. Measurement of rapidly exchangeable cellular calcium in the perfused beating rat heart. Proc. Natl. Acad. Sci. USA. 78:5665-5668.

24. Hunter, D. F., R. A. Haworth, and H. A. Berkoff. 1982. Cellular calcium turnover in the perfused rat heart. Modulation by caffeine and procaine. Circ. Res. 51:363-370.

25. Gøtzsche, O. 1985. Abnormal myocardial calcium uptake in streptozotocin-diabetic rats. Evidence for a direct insulin effect in catecholamine sensitivity. Diabetes. 34:28 $\overrightarrow{7}-290$.

26. Djurhuus, R. 1981. Ornithine decarboxylase assay based upon the retention of putrescine by a strong cation-exchange paper. Anal. Biochem. 113:352-353.

27. Nawata, H., R. S. Yamamoto, and L. A. Poirier. 1980. Ornithine decarboxylase induction and polyamine levels in the kidney of estradiol-treated castrated male rats. Life Sci. 26:689-698.

28. Lowry, O. H., H. J. Rosebrough, A. L. Farr, and R. J. Randall. 1951. Protein measurement with the Folin phenol reagent. J. Biol. Chem. 193:265-275.

29. Metcalf, B. W., P. Bey, C. Danzin, M. J. Jung, P. Casara, and J. P. Vevert. 1978. Catalytic irreversible inhibition of mammalian ornithine decarboxylase (EC 4.1.1.17) by substrate and product analogues. J. Am. Chem. Soc. 100:2551-2553.

30. Holland, C. E., Jr., and R. E. Olson. 1975. Prevention by hypothermia of paradoxical calcium necrosis in cardiac muscle. $J$. Mol. Cell. Cardiol. 7:917-928.

31. Baker, J. E., G. R. Bullock, and D. J. Hearse. 1983. The temperature dependence of the calcium paradox: enzymatic, functional and morphological correlates of cellular injury. J. Mol. Cell. Cardiol. 15:393-411.

32. Hunt, W. G., and R. J. Willis. 1985. Calcium exposure required for the full expression of injury in the calcium paradox. Biochem. Biophys. Res. Commun. 126:901-904.

33. Costa, M., and J. Nye. 1978. Calcium, asparagine and cAMP are required for ornithine decarboxylase activation in intact Chinese hamster ovary cells. Biochem. Biophys. Res. Commun. 85:1156-1164.

34. D'Amore, P., and D. Shepro. 1978. Calcium flux and ornithine decarboxylase activity in cultured endothelial cells. Life Sci. 22:571576.

35. Gibbs, J., C.-Y. Hsu, G. Terasaki, and G. Booker. 1980. Calcium and microtubule dependence for increased ornithine decarboxylase activity by $\beta$-adrenergic agonists, dibutyryl cyclic AMP or serum in a rat astrocytoma cell line. Proc. Natl. Acad. Sci. USA. 77:995-999.

36. Russell, D. H. 1985. Ornithine decarboxylase: a key regulatory enzyme in normal and neoplastic growth. Drug Metab. Rev. 16:1-88.

37. Langdon, R. C., P. Fleckman, and J. McGuire. 1984. Calcium stimulates ornithine decarboxylase in cultured mammalian epithelial cells. J. Cell Physiol. 118:39-44. 
38. Chapman, R. A., G. C. Rodrigo, J. Tunstall, R. J. Yates, and P. Busselen. 1984. The calcium paradox of the heart: a role for intracellular sodium ions. Am. J. Physiol. 247:H874-H879.

39. Dhalla, N. S., L. E. Alto, and P. K. Singal. 1983. Role of $\mathrm{Na}^{+}-\mathrm{Ca}^{2+}$ exchange in the development of cardiac abnormalities due to calcium paradox. Eur. Heart J. 4(Suppl. H):51-56.

40. Ruano-Arroyo, G., C. Gerstenblith, and E. G. Lakatta. 1984 Calcium paradox in the heart is modulated by cell sodium during the calcium-free period. J. Mol. Cell. Cardiol. 16:783-793.

41. Tunstall, J., P. Busselen, G. C. Rodrigo, and R. A. Chapman. 1986. Pathways for movements of ions during calcium-free perfusion and the induction of the 'calcium paradox'. J. Mol. Cell. Cardiol. 18:241-254.

42. Alto, L. E., and N. S. Dhalla. 1981. Role of changes in micro- somal calcium uptake in the effects of reperfusion of $\mathrm{Ca}^{2+}$-deprived rat hearts. Circ. Res. 48:17-24.

43. Lamers, J. M. J., and T. J. C. Ruigrok. 1983. Diminished $\mathrm{Na}^{+} / \mathrm{K}^{+}$and $\mathrm{Ca}^{2+}$ pump activities in the $\mathrm{Ca}^{2+}$ depleted heart: possible role in the development of $\mathrm{Ca}^{2+}$ overload during the $\mathrm{Ca}^{2+}$ paradox. Eur. Heart J. 4(Suppl. H):73-79.

44. Lamers, J. M. J., J. T. Stinis, and T. J. C. Ruigrok. 1984. Biochemical properties of membranes isolated from calcium-depleted rabbit hearts. Circ. Res. 54:217-226.

45. Ruigrok, T. J. C., A. B. T. J. Boink, F. Spies, F. J. Blok, A. H. J. Maas, and A. N. E. Zimmerman. 1978. Energy dependence of the calcium paradox. J. Mol. Cell. Cardiol. 10:991-1002.

46. Ganote, C. E., and W. G. Nayler. 1985. Contracture and the calcium paradox. J. Mol. Cell. Cardiol. 17:733-745. 